\title{
Technostress: \\ Pengertian, Penyebab dan Koping Pustakawan
}

\author{
Suryanto $^{\left.1^{*}\right)}$, Twista Rama Sasi ${ }^{2}$ \\ ${ }^{1}$ SMA Negeri 5 Magelang, Jl. Barito II Sidotopo, Magelang, Indonesia \\ ${ }^{2}$ UPT Perpustakaan Stikes Bethesda Yakkum, Jl. Johar Nurhadi No.6, \\ Kotabaru, Gondokusuman, Kota Yogyakarta, DIY \\ *Korespondensi: suryanto.uya.dhuha@gmail.com
}

\begin{abstract}
Abstrak
Nowadays, technology is growing so fast which cause all of the human life. Library is a kind of work which can't lost from the impact of technological progress. Nevertheless, not all librarians are able to adapt quickly with the change and development of technology, so it can cause the problem for them, one of them is technostress. Technostress is an uncomfortable condition which which caused by the inability of individuals to adapt with the technological changes or a condition of individual dependency on technology which cause the uncomfortable both physical and psychic. Technostress is caused by several factors that is the development of technology, the lack of standardization, the lack of individual training (librarians) against the technology and equipment used, the technology reliability, the increased of work load which given to each librarian, the appearance of role change from the librarian. Another opinion says that which resulted in the occurrence of technostress there are five components, namely techno-overload, techno-invasion, techno-complexity, techno-insecurity, dan techno-uncertainty. Coping strategies which can be applied by librarians in facing technostress can be long-term coping methods, which is considered to be more effective to reduce the impact of technostress and short-term coping methods which is effective to overcome technostress temporarily.
\end{abstract}

Keywords: Technostress, Librarian, Library, 


\section{Latar Belakang}

Dewasa ini teknologi berkembang semakin pesat yang mempengaruhi semua sendi kehidupan manusia. Baik dalam menjalankan kehidupan seharihari maupun dalam dunia pekerjaan, dalam menjalani profesi. Oleh karena itu dengan adanya perubahan teknologi tersebut, kita diharapkan mampu mengubah perilaku dan cara kerja kita agar dapat menyesuaikan diri dengan perkembangan teknologi yang terjadi, dengan senantiasa memperbaharui kemampuan dan ketrampilan teknis kita. Pada lebih dari dua dasa warsa terakhir ini kemajuan teknologi terjadi dengan begitu pesatnya, bahkan menurut Marilyn L. Laspinas mengatakan bahwa "In the 21th century, the technological momentum has increased far beyond our expectations"1 yang berarti bahwa pada abad ke-21 ini merupakan sebuah momentum teknologi, dimana telah terjadi perkembangan teknologi yang jauh melampaui harapan masyarakat. Melalui pemanfaatan teknologi tersebut memungkinan suatu aktifitas pekerjaan dapat dilakukan dengan cara yang lebih efektif dan efisien.

Perpustakaan merupakan salah satu bidang pekerjaan yang tidak luput dari dampak perkembangan kemajuan teknologi. Melalui pemanfaatan teknologi informasi di perpustakaan dapat meningkatkan mutu layanan perpustakaan bagi para pemustaka. Hal senada diungkapkan oleh Moreover, Murthy \& Choloin (2003) dalam Marilyn L. Laspinas ${ }^{2}$ yang mengilustrasikan "the technological trends and challenges have also been a leading force in improving and enhancing library service" yang berarti bahwa kecenderungan dan tantangan teknologi merupakan suatu kekuatan utama dalam meningkatkan layanan perpustakaan. Lebih lanjut Moreover \& Cholin mengatakan bahwa suatu aplikasi otomasi perpustakaan merupakan hal yang sangat baik untuk meningkatkan keefektifan kegiatan perpustakaan seperti: pengadaaan, sirkulasi, katalogisasi, referensi, dan control terbitan berseri. "the application of library automation has immensely improved the effectiveness of library activities such as acquisition, circulation, cataloguing, reference, and

\footnotetext{
${ }^{1}$ Marilyn L. Laspinas, “Technostress: Trends and Challenges In The $21^{\text {st }}$ Century Knowledge Management”, European Scientific Journal, No.2, Vol.11, Januari 2015., hlm.206.

${ }^{2} \mathrm{Ibid}, \mathrm{hlm} .206$
} 
serials control. ${ }^{3}$ Dengan kata lain bahwa teknologi informasi merupakan hal yang penting di dalam meningkatkan efektifitas seluruh kegiatan layanan perpustakaan baik yang berada di barisan back office maupun front office. Fungsi teknologi informasi khususnya komputer, memiliki kemampuan yang luar biasa dalam rangka melakukan proses penyimpanan, pengolahan, perekaman, dan proses menyajikan kembali sejumlah informasi yang telah disimpan dan direkamnya, sehingga pemanfaatan teknologi informasi di perpustakaan menjadi sesuatu yang tidak dapat dihindarkan di dalam perpustakaan dalam rangka menyediakan informasi bagi para pemustaka secara cepat dan tepat dalam era informasi dimana informasi harus diberikan dengan cepat agar tidak ketinggalan informasi yang berkembang dengan semakin kompleks ${ }^{4}$.

Sementara itu di sisi lain, perkembangan teknologi tidak akan berarti apabila tidak ada peran manusia. Manusia selalu ada di balik perkembangan teknologi sekaligus manusia juga yang mengoperasikan teknologi tersebut. Sehingga sumber daya manusia khususnya pustakawan perlu membekali diri dengan kemampuan dalam bidang teknologi tersebut agar dapat menyesesuaikan diri dengan perkembangan teknologi. Teknologi akan mengubah bagaimana cara seseorang dalam bekerja dan belajar, sesuai dengan pendapat yang dikemukakan David-Millis \& Brand dalam Prabhakaran \& Mishra yang mengatakan bahwa "Technology changes the way people work and learn. As the role of technology is being and is constantly being improved, change is inevitable"s.

Namun demikian tidak semua pustakawan mampu beradaptasi dengan perubahan dan perkembangan teknologi yang begitu cepat, sehingga dapat menimbulkan permasalahan bagi mereka, National Safety Council bahkan menyatakan bahwa perkembangan teknologi dapat mempengaruhi kemampuan kita untuk dapat mempertahankan produktivitas bahkan kita

\footnotetext{
${ }^{3}$ Ibid, hlm. 206

${ }^{4}$ Pawit M. Yusup \& Priyo Subekti, Teori \& Praktik Penelusuran Informasi (Information Retrieval), (Jakarta: Kencana, 2010), ed.1, cet.1, hlm.234.

${ }^{5}$ Ajit Prabhakaran \& Heramb Kumar Mishra, "Technological Change in Libraries: The Evolution of Technistres”, Journal of Arts, Science \& Commerce, vol.III, Issue-1, Januari 2012, hlm.132.
} 
hanya memiliki sedikit bahkan sama sekali tidak memiliki kemampuan untuk mengendalikan atau dengan kata lain, pustakawanpun akan menjadi lebih rentan terhadap stres ${ }^{6}$. Adapun stres yang ditimbulkan karena pengaruh teknologi disebut sebagai technostress. Technostress merupakan stres yang sering dialami oleh pustakawan. Agar kejadian technostress pustakawan tersebut tidak sampai mengganggu kinerja sebagai pustakawan, maka seorang pustakawan harus mempunyai kemampuan untuk mengurangi stress teknologi tersebut. Suatu cara yang digunakan oleh seseorang individu untuk mengurangi stres dinamakan dengan koping?

\section{Rumusan Masalah}

Berdasarkan latar belakang di atas maka dapat dirumuskan permasalahan sebagai berikut:

1. Apakah pengertian dari technostres pustakawan?

2. Apa saja yang menyebabkan technostress pustakawan?

3. Bagaimana koping pustakawan dalam mengadapi technostress?

\section{Pembahasan}

\section{Pengertian}

\section{a) Pengertian Stres}

Sebelum membahas mengenai technostress terlebih dahulu perlu memahami makna stres secara umum. Menurut Seaward, stres dapat dimaknai sebagai ketidakmampuan manusia dalam mengatasi ancaman yang dihadapi oleh mental, fisik, emosional, dan spiritual manusia, yang pada suatu saat dapat mempengaruhi kesehatan fisik manusia tersebut. Stres merupakan persepsi seseorang terhadap situasi dan kondisi di dalam lingkungan mereka. Sebagai suatu persepsi, maka antara satu orang dengan yang lain tidak sama. Persepsi seseorang terhadap stres timbul dari rasa takut atau marah. Hal tersebut dapat tergambarkan dalam bentuk sikap seseorang yang menjadi

\footnotetext{
${ }^{6}$ Brian Luke Seaward, Manajemen Stres, (Jakarta: EGC, 2004), hlm.1-2.

${ }^{7}$ Rasmun, Stres Koping, dan Adaptasi, (Jakarta: Sagung Seto, 2004), hlm. 29.
} 
tidak sabar, merasa frustasi, iri, menjadi tidak ramah, mengalami depresi dan kebimbangan, kecemasan, perasaan bersalah, perasaan khawatir dan sikap yang apatis. Apabila stres terjadi di tempat kerja maka akan muncul dalam bentuk sikap yang pesimistis, merasa tidak puas, produktivitas kerja menurun, dan sering absen atau membolos. Perilaku, sikap, dan emosi seseorang yang disebabkan oleh stres tersebut dapat menimbulkan gangguan pada kesehatan ${ }^{8}$.

Pendapat senada juga dikemukakan oleh Hans Selye yang dikutip oleh Dadang Hawari, yang mengatakan bahwa stres merupakan suatu bentuk respon tubuh yang bersifat non spesifik terhadap setiap tuntutan beban yang ditanggung seseorang ${ }^{9}$. Sebagai contoh, misalnya ketika seseorang pustakawan mempunyai beban terhadap suatu pekerjaan yang berlebihan, apabila pustakawan tersebut dapat mengatasinya maka dia tidak akan mengalami gangguan pada fungsi organ tubuhnya atau dapat dikatakan bahwa pustakawan tersebut tidak mengalami stres. Begitu pula sebaliknya apabila pustakawan tersebut tidak mampu mengatasi beban pekerjaannya maka dapat menimbulkan gangguan fungsi organ tubuh atau dapat dikatakan mengalami stres. Stres tidak hanya berdampak pada gangguan fungsional organ tubuh tetapi dapat pula mengakibatkan gangguan kejiwaan misalnya kecemasan atau depresi.

Berdasarkan beberapa pengertian stres di atas maka dapat disimpulkan bahwa stress merupakan suatu respon tubuh yang bersifat non spesifik berupa ketidakmampuan manusia dalam mengatasi ancaman yang dihadapi oleh mental, fisik, emosional, dan spiritual manusia, yang pada suatu ketika dapat mempengaruhi kesehatan fisik. Setiap orang mempunyai respon yang berbeda-beda terhadap sumber stres sehingga ada sebagian orang yang terkena stress sementara sebagian yang lain tidak mengalami gangguan stress.

\footnotetext{
${ }^{8}$ Brian Luke Seaward, Manajemen Stres, hlm. .2-3

${ }^{9}$ Hawari, Dadang. Manajemen Stres Cemas dan Depresi. Jakarta: Balai Penerbit Fakultas Kedokteran Universitas Indonesia, 2001. hlm.17-18
} 


\section{b) Pengertian Technostress}

Stres terhadap teknologi secara khusus disebut sebagai technostress. Istilah technostress pertama kali diperkenalkan pada tahun 1984 oleh seorang psikolog klinis bernama Dr. Craig Brod, yang mendefinisikan technostress sebagai: "technostress is a modern disease of adaptation caused by an inability to cope with the new computer technologiest in a healthy manner. It manifests itself in two distinct but related ways: in the struggle to accept computer technology, and in the more specialized form of over-identification with computer technology". Broad beranggapan bahwa technostress merupakan suatu bentuk gangguan atau penyakit yang disebabkan karena ketidakmampuan menggunakan teknologi baru komputer dengan cara yang tepat, yang dapat berupa dua hal yang berbeda namun saling berkaitan, yaitu: yang pertama berupa suatu bentuk usaha untuk dapat menerima teknologi komputer dan pada manifestasi kedua yaitu adalah identifikasi yang berlebihan (pemanfaatan yang berlebihan) terhadap teknologi komputer ${ }^{10}$.

Berbeda dengan pendapat Broad tersebut, Clark \& Kalin mengatakan bahwa, "the real definition of technostress is resistance to change". Selanjutnya Clark \& Kalin mengatakan bahwa "technology is not the culprit because computer and technologies are just tools and stress is a natural reaction". Dengan kata lain bahwa teknologi bukan merupakan pelaku/penyebab stres, oleh karena komputer dan teknologi hanyalah merupakan suatu alat bantu sedangkan stres merupakan suatu bentuk reaksi alamiah. Selanjutnya Clark \& Kalin menyarankan agar seseorang dapat mengelola technostress, dengan cara mengelola perubahannya bukan pada teknis teknologinya ${ }^{11}$.

Berdasarkan beberapa pendapat mengenai pengertian technostress di atas maka dapat dikatakan bahwa technostress merupakan suatu kondisi ketidaknyamanan yang disebabkan karena ketidakmampuan individu dalam rangka beradaptasi terhadap perubahan teknologi dan atau suatu

${ }^{10}$ Ungku Norulkamar Ungku Ahmad, dkk, "The Impact of Technostress on Organisational Commitment Among Malaysian Academic Librarians", Singapore Journal of Library \& Information Management, vol.38 th.2009, hlm. 105.

${ }^{11} \mathrm{Ibid}$, hlm. 105. 
kondisi ketergantungan individu terhadap teknologi yang mengakibatkan ketidaknyamanan baik secara fisik maupun psikis. Sebagai suatu bentuk stres, maka respon technostress pada satu individu dengan individu yang lain akan berbeda-beda, tergantung pada kemampuan seseorang individu untuk beradaptasi. Hal tersebut berlaku pula bagi pustakawan, apakah seorang pustakawan mempunyai kemampuan beradaptasi terhadap perkembangan teknologi ataukah seorang pustakawan tersebut tidak mempunyai kemampuan beradaptasi terhadap perubahan perkembangan teknologi yang terjadi.

Menurut Kuppersmith, Weil \& Rosen seperti yang dikutip oleh Ahmad mengatakan bahwa Technostress dapat meyebabkan kecemasan dan pengaruh negatif pada pikiran, perilaku, tingkah laku dan tubuh seorang pustakawan $^{12}$. Pemanfaatan berbagai jenis teknologi baru di perpustakaan dapat menimbulkan tekanan terhadap pustakawan, Hal tersebut senada dengan pendapat yang disampaikan oleh Bichteler, Davis-Millis, Kupersmith dalam Ahmad bahwa tekanan yang besar atau technostress yang dialami pustakawan tersebut diakibatkan karena penggunaan suatu sistem yang terintegrasi komputer, CD-ROM dan berbagai database, penggunaan internet dan World Wide Web, serta perubahan teknologi yang berlangsung secara cepat ${ }^{13}$

\section{Penyebab Technostress Pustakawan}

Seperti kejadian stres pada umumnya terjadi karena suatu stressor, maka technostress-pun dapat terjadi karena beberapa penyebab. Menurut Lisa Ennis dalam thesisnya yang berjudul "Technostress in the Reference Environment", yang dikutip oleh Prabhakaran \& Mishra ${ }^{14}$, mengungkapkan terdapat enam hal spesifik yang menyebabkan technostres bagi pustakawan. Adapun keenam penyebab technostress tersebut adalah.

a) Laju perkembangan teknologi

b) Kurangnya standarisasi.

\footnotetext{
${ }^{12} \mathrm{Ibid}, \mathrm{hlm} .104$

${ }^{13}$ Ibid, hlm.104

${ }^{14}$ Ajit Prabhakaran \& Heramb Kumar Mishra, “Technological change”.., hlm.1.
} 
c) Kurangnya latihan bagi pustakawan terhadap teknologi dan peralatan yang akan digunakan.

d) Keterandalan suatu teknologi.

e) Adanya peningkatan beban pekerjaan yang diberikan pada masingmasing pustakawan.

f) Munculnya perubahan peran dari pustakawan.

Sementara itu, Tarafdar, Tu, Ragu-Nathan, dan Ragu-Nathan yang dikutip oleh Ahmad ${ }^{15}$, mengidentifikasikan lima komponen sebagai pencetus technostress, yakni:

a) Techno-overload, yakni suatu situasi dimana pengguna Teknologi Informasi dan Komunikasi terpaksa harus bekerja dengan lebih cepat dan lebih lama.

b) Techno-invasion, yaitu suatu kondisi dimana pengguma teknologi informasi dan komunikasi merasa bahwa mereka dapat dihubungi kapan saja secara terus menerus, sehingga menyebabkan bias antara kepentingan yang terkait dengan pekerjaan maupun dalam konteks pribadi.

c) Techno-complexity, suatu kondisi dimana pengguna teknologi informasi dan komunikasi merasa bahwa kemampuan yang mereka miliki tidak memadai, hal tersebut dikarenakan karena hal-hal yang berkaitan dengan tingkat kerumitan pada teknologi informasi dan komunikasi. Sebagai suatu konsekuensi, bahwa mereka terpaksa meluangkan waktu dan berusaha untuk mempelajari dan memahami aspek-aspek yang berkaitan dengan teknologi informasi dan komunikasi.

d) Techno-insecurity, suatu kondisi dimana pengguna teknologi informasi dan komunikasi merasa terancam kehilangan pekerjaan, baik karena perannya digantikan teknologi atau karena digantikan oleh orang lain yang mempunyai kemampuan yang lebih baik dalam hal teknologi informasi dan komunikasi.

e) Techno-uncertainly, yaitu suatu kondisi dimana pengguna teknologi hlm.106.

${ }^{15}$ Ungku Norulkamar Ungku Ahmad, dkk, "The Impact of Technostress on Organisational”..., 
informasi dan komunikasi merasakan ketidakpastian dan keresahan sejak teknologi informasi dan komunikasi secara terus menerus berubah dan mengalami perbaikan.

\section{Koping Pustakawan dalam Menghadapi Technostress}

Sebagai salah satu bentuk dari stres, gejala yang muncul dari kejadian technostress dapat dibagi kedalam dua bentuk. Menurut Harper yang dikutip oleh Ahmad, bentuk dari technostress yang dialami pustakawan dapat terlihat pada: gangguan fisik dan gangguan psikologis. Gejala-gejala fisik yang terlihat seperti, sakit kepala, ketegangan pada punggung, ketegangan pada mata, cedera karena ketegangan yang berulang seperti sindrom carpal turner, serta adanya gangguan pada otot. Sementara bentuk gangguan yang terjadi pada psikologis merupakan bentuk technostres yang dialami pustakawan meliputi perasaan menarik diri, informasi yang berlebihan, overidentify terhadap teknologi pada saat melakukan tugas rutin. Kekuatiran bahwa peran pustakawan akan tergantikan oleh teknologi, perasaan iri diantara para pustakawan karena perbedaan kemampuan teknologi informasi, serta adanya ketidakpastian peran pustakawan ${ }^{16}$.

Technostress yang dialami oleh pustakawan apabila tidak diantisipasi akan mengganggu kinerja. Oleh karena itu pustakawan perlu memahami koping terhadap technostress. Menurut Rasmun, koping merupakan suatu proses dalam rangka menghadapi kondisi stresfull yang harus dilalui oleh seseorang, sebagai bentuk respon terhadap situasi yang mengancam dirinya baik fisik maupun psikologis. Lebih lanjut Rasmun menenjelaskan bahwa disadari maupun tidak disadari setiap orang secara alamiah sudah menggunakan strategi koping dalam menghadapi stres termasuk stres karena teknologi atau technostress. Strategi koping tersebut merupakan sebuah cara yang ditempuh untuk dapat mengubag lingkungan atau kondisi atau dengan kata lain untuk menyelesaikan masalah yang tengah dihadapi, pada kasus technostress maka masalah yang dihadapi berkaitan dengan teknologi.

${ }^{16}$ Ungku Norulkamar Ungku Ahmad, dkk, "The Impact of Technostress on Organisational “..., hlm 108. 
Koping yang dimaksudkan adalah usaha perubahan kognitif dan perilaku secara konstan dalam rangka menyelesaikan kondisi stres atau khususnya technostress yang dihadapi. Koping yang efektif menghasilkan adaptasi yang menetap yang merupakan kebiasaan baru dan memberikan perbaikan terhadap situasi sebelumnya, sedangkan koping yang tidak efektif merupakan perilaku menyimpang dari keinginan normatif dan merugikan diri sendiri, orang lain dan lingkungan ${ }^{17}$.

Koping dibedakan menjadi koping psikologis dan koping psikososial. Koping psikologis muncul dari persepsi seseorang terhadap stressor, seberapa besar ancaman yang diterima individu terhadap stressor yang diterimanya. Untuk technostres dapat berarti seberapa besar ancaman yang dirasakan oleh pustakawan terhadap teknologi khususnya dalam konteks di perpustakaan. Sedangkan koping psiko-sosial merupakan suatu rekasi psiko-sosial terhadap adanya rangsangan stres yang diterima atau dihadapi. Menurut Stuart dan Sundeen seperti yang dikutip oleh Rasmun, ada dua kategori koping yang dapat digunakan, yakni yang pertama adalah reaksi yang berorientasi pada tugas (task oriented reaction), merupakan cara yang digunakan untuk menyelesaikan masalah, konflik dan memenuhi kebutuhan dasar. Reaksi yang ditimbulkan yaitu: perilaku menyerang (melakukan perlawanan dalam rangka memprtahankan integritas pribadi), perilaku menarik diri (withdrawl), dan kompromi, sementara reaksi yang kedua adalah reaksi yang berorientasi pada ego, koping pada reaksi ego bekerja secara tidak sadar sehingga pnyelesaian yang diperoleh sukar dan tidak realistis, misalnya mekanisme pertahanan diri kompensasi, pengalihan, pengingkaran, dan sebagainya ${ }^{18}$.

Selanjutnya bagaimana metode koping yang dapat dipergunakan pustakawan dalam menghadapi technostress dalam dunia pekerjaan. Dengan mengadaptasi pendapat yang ditawarkan oleh Bell yang dikutip oleh Rasmun ${ }^{19}$, ada dua metode yang dapat dipergunakan oleh pustakawan.

\footnotetext{
${ }^{17}$ Rasmun, Stres, Koping..., hlm 29-30.

${ }^{18}$ Rasmun, Stres, Koping..., hlm.30-36

${ }^{19}$ Rasmun, Stres, Koping..., hlm 37-38.
} 
a. Metode koping jangka panjang

Metode ini dapat dipergunakan oleh pustakawan dalam mengadapi technostress, metode ini merupakan metode yang konstruktif karena menawarkan cara penanganan yang efektif dan realistis. Cara yang dapat ditempuh oleh pustakawan, antara lain:

1) Mengungkapkan apa yang sedang dirasakan dan dialami kepada orang lain, baik dengan teman, keluarga atau pustakawan yang lain mengenai permasalahan dan kondisi yang tengah dihadapi. Dengan mengkomunikasikan permasalahan yang sedang dihadapi akan meringankan beban pustakawan, dan diharapkan akan akan muncul solusi dari permasalahan yang dirasakan.

2) Mencoba mencari informasi lebih banyak mengenai teknologi, dapat dilakukan dengan belajar mandiri mengenai aplikasi suatu teknologi, bertanya kepada pustakawan yang lebih ahli dalam teknologi, berdiskusi dengan pustakawan lain mengenai bagaimana menghadapi teknologi tersebut khususnya teknis teknologinya, atau pustakawan dapat mengusulkan untuk dapat dilakukan pelatihan-pelatihan sebelum suatu teknologi diimplementasikan di perpustakaan maupun pelatihan lanjutan ketika terjadi perubahan dan perkembangan teknologi, sehingga seorang pustakawan siap dan tidak stres mengahadapi teknologi yang akan dipergunakan tersebut. Perlunya penjelasan mengenai perubahan peran yang harus dilakukan pustakawan sehingga pustakawan tidak merasa kuatir dan dapat melakukan inovasi-inovasi dalam pekerjaannya ketika teknologi diterapkan di perpustakaan.

3) Melakukan latihan fisik guna mengurangi ketegangan dan masalah, misalnya dengan berolahraga, meditasi, yoga, dan sebagainya.

4) Belajar dari pengalaman pustakawan lain yang pernah mengalami teknostress sebelumnya, sehingga dapat mengambil pelajaran bagaimana cara mengahadapi tekanan dan penyelesaian masalah tersebut. 
b. Metode koping jangka pendek

Metode ini cukup efektif untuk mengatasi tekanan stress untuk sementara waktu tetapi tidak untuk jangka waktu yang lama. Contoh dari upaya koping jangka pendek adalah.

1) Melamun dan fantasi.

2) Mencoba melihat dengan cara humor dari situasi yang tidak menyenangkan.

3) Tidak ragu, dan merasa yakin bahwa semua akan kembali normal.

4) Menangis, merokok, banyak tidur.

5) Sementara waktu beralih pada aktifitas lain yang tidak berhubungan langsung dengan teknologi untuk melupakan sejenak permasalahan yangsedang dihadapi.

\section{Simpulan}

Sesuai dengan pembahasan diatas berangkat dari permasalahan yang diangkat, maka dapat diambil tiga simpulan sebagai berikut.

1. Technostress adalah salah satu jenis stres yang disebabkan karena teknologi yaitu merupakan suatu kondisi ketidaknyamanan yang disebabkan karena ketidakmampuan individu dalam rangka beradaptasi terhadap perubahan teknologi dan atau suatu kondisi ketergantungan individu terhadap teknologi yang mengakibatkan ketidaknyamanan baik secara fisik maupun psikis.

2. Technostress disebabkan beberapa kondisi, menurut Lisa Ennis ada enam penyebab yaitu: laju perkembangan teknologi, kurangnya standarisasi, kurangnya latihan individu (pustakawan) terhadap teknologi dan peralatan yang akan digunakan, keterandalan suatu teknologi, adanya peningkatan beban pekerjaan yang diberikan pada masing-masing individu (pustakawan), munculnya perubahan peran dari pustakawan. Sementara menurut Tarafdar, Tu, Ragu-Nathan, dan Ragu-Nathan yang dikutip oleh Ahmad, mengidentifikasikan lima komponen sebagai pencetus technostress, yakni: techno-overload, techno-invasion, techno- 
complexity, techno-insecurity, dan techno-uncertainty.

3. Strategi koping yang dapat diterapkan oleh pustakawan dalam mengahadapi technostress dapat berupa metode koping jangka panjang, yang dianggap lebih efektif mengurangi dampak technostress dan metode koping jangka pendek, dimana metode ini cukup efektif mengatasi technostress untuk sementara waktu.

\section{Daftar Pustaka}

Ahmad, Ungku Norulkamar Ungku, dkk, “The Impact of Technostress on Organisational Commitment Among Malaysian Academic Librarians", Singapore Journal of Library \& Informatin Management, vol.38, 2009.

Hawari, Dadang. Manajemen Stres Cemas dan Depresi. Jakarta: Balai Penerbit Fakultas Kedokteran Universitas Indonesia, 2001.

Laspinas, Marilyn L. “Technostress:Trends and Challenges In The $21{ }^{\text {st }}$ Century Knowledge Management”, European Scientific Journal, Januari 2015 edition vol.11 No.2., 2015

Prabhakaran, Ajit \& Heramb Kumar Mishra, “Technological Change in Linraries: The Evolution of Technostress", dalam Journal of Arts, Science \& Commerce, vol.III, Issue-1, Januari , 2012.

Seaward, Brian Luke, Manajemen Stres, Jakarta: EGC, 2004.

Rasmun, Stres, Koping, dan Adaptasi, Jakarta: Sagung Seto, 2004.

Yusup, Pawit M. \& Priyo Subekti, Teori \& Praktik Penelusuran Informasi (Information Retrieval), ed.1, cet.1, Jakarta: Kencana, 2010. 